\title{
Microgranular Acute Promyelocytic Leukemia
}

National Cancer Institute

\section{Source}

National Cancer Institute. Microgranular Acute Promyelocytic Leukemia. NCI Thesaurus.

Code C27757.

Acute promyelocytic leukemia in which the promyelocytes in the peripheral blood have paucity or absence of cytoplasmic granules and characteristic bilobed nuclei. 